\title{
CSCW and Social Computing
}

\section{The Past and the Future}

\author{
Michael Koch • Gerhard Schwabe • \\ Robert O. Briggs
}

Published online: 3 March 2015

(C) Springer Fachmedien Wiesbaden 2015

\section{Background/Past}

Research on IT support for collaborative work has a long history. Researchers have approached the topic from many directions using many perspectives. The field split into multiple subfields, each focused on different goals, and each with its own terminology.

One subfield is Computer-Supported Collaborative Work $(C S C W)$. The origins of CSCW trace back to a workshop organized by Irene Greif and Paul Cashman in 1984, where researchers from different disciplines met to exchange ideas, share results, and to join forces to better understand how IT could be used to improve and enhance group outcomes. A variety of definitions for CSCW have flowered, but they converge to similar concepts: "In its most general form, CSCW examines the possibilities and effects of technological support for humans involved in collaborative group communication and work processes" (Bowers and Benford 1991, p. 5).

\section{Prof. Dr. M. Koch ( $\square)$}

Cooperation Systems Center Munich, Bundeswehr University

Munich, Werner-Heisenberg-Weg 39, 85577 Neubiberg,

Germany

e-mail: michael.koch@unibw.de

URL: http://www.kooperationssysteme.de

Prof. Dr. G. Schwabe

Department of Informatics, University of Zürich,

Binzmuehlestrasse 14, 8050 Zurich, Switzerland

e-mail: schwabe@ifi.uzh.ch

URL: http://www.ifi.uzh.ch/imrg/

Prof. R. O. Briggs

College of Business Administration, San Diego State University,

5500 Campanile Drive, San Diego, CA 92182-8230, USA

e-mail: robertowenbriggs@gmail.com

URL: http://cbaweb.sdsu.edu
By studying work processes, and by developing and testing tools to support them, numerous technologies and tools have been developed and tested, and groundbreaking insights into understanding the process of collaboration and the process of introducing tools for supporting communication and collaboration have been obtained. For example, the utility of coexistence and awareness for some kinds of cooperative work is now well understood, and technological support for those items have been prototyped, tested, and diffused into the field (Dourish and Belotti 1992; Koch and Gross 2006). The concept of coordination has been researched, and support for coordination is now ubiquitous in the workplace (Malone and Crowston 1992). A variety of models for understanding the role of communication have been advanced, e.g. the context-oriented communication model by Misch (2001) or the Cooperative Work Framework by Dix et al. (1993, pp. 465 f), and each provides valuable insights for practitioners and researcher.

$\mathrm{CSCW}$ research also helped to promulgate useful methodological points-of-view and methods to the information sciences. CSCW researchers were leaders in the diffusion of ethnographic studies in the IS discipline, and contributed to the growing perspective that people are not just "end-users" of information systems, but are an integral part of these systems, and so should be active participants in the processes by which systems are designed and deployed (Brenner et al. 2014).

A different stream of research, now called Group Support Systems (GSS), emerged in the early 1970s in response to the need for very large numbers of stakeholders to converge on a single, validated set of computer system requirements. Daniel Teichroew, Jay Nunamaker, and others PSL/PSA, a system where users would write their requirements in a structured-English format akin to Pseudcode, and then feed the requirements into an 
automatic analyzer to be checked for completeness, consistency, and correctness. The system worked as far as it went, but was not an operationally feasible approach. The PSL/PSA stream branched; Teichroew went on to invent Computer Assisted Software Engineering (CASE), and Nunamaker went on to invent GSS. A GSS supports collaborative work practices with shared editors and polling tools optimized for idea generation, convergence, organization, and evaluation. The first GSS tool was an electronic brainstorming tool developed in the job control language of a VAX minicomputer (Nunamaker et al. 1976).

While CSCW research began with a focus on small groups, typically three to six people, GSS researchers were focused on larger groups, typically tens to hundreds of people. GSS tools were integrated to help a group move seamlessly from activity to activity as they executed their plan. Early research showed that GSS users in many domains who were led by expert facilitators could routinely save $50 \%$ of labor hours and reduce project cycle times by $90 \%$ while producing higher quality work products. However, after a decade of field research it became clear that these benefits were usually only realized in groups led by expert facilitators, who were scarce and expensive. Most groups, therefore, could not realize the potential of the technology. That realization gave rise to discipline called Collaboration Engineering.

Collaboration Engineering $(C E)$ is an approach to designing collaborative work systems for high-value tasks, and transferring these practices to practitioners to execute for themselves without ongoing support from an expert facilitator (de Vreede and Briggs 2009). It was born in 2000 on a desert hike when Robert O. Briggs and G. J. de Vreede, both GSS researchers and expert facilitators, discovered that they had independently developed tacit, yet overlapping sets of techniques for moving groups successful through a processes to their goals. They began work with other researchers to externalize the tacit understandings of expert facilitators, to codify them into discrete chunks of learnable knowledge, and to distill them into the smallest amount of knowledge one would need in order to repeat the effects produced by experts (Briggs et al. 2003). Since that time, structured methodologies for CE have been developed and tested (Kolfschoten and de Vreede 2009), a six-layered conceptual model of collaboration has been advanced (Briggs et al. 2014), a number of theoretical models have been developed to predict and explain the effects of design choices on group dynamics, and researchers have figured out a way to package some kinds of collaboration techniques with collaboration technology in a form that non-expert can use successfully with no training on either the tools or the techniques (Briggs et al. 2013).

Finally, Social Computing (SC) refers to supporting social interaction and socialization by the use of IT systems. Within that context the term Social Software is used for tools or services that "support, extend or derive added value from human social behavior" (Coates 2005).

Where CSCW often has focused on groups of ten, and GSS and CE have focused on groups of tens-to-hundreds, Social Computing often involves tens-of-thousands to millions of people. SC research therefore addresses issues that emerge on a much larger scale - e.g., cultural changes that are enabled by new technology. Social Computing focuses more on communication than on coordination and collaboration. Additionally, Social Computing often focuses not on the work place, but in the consumer domain. Methodically, the focus of CSCW on ethnographic studies (of small work groups) is contrasted by Social Computing studies of mass participation. Much exploratory research will be required to understand the profound changes Social Computing may have wrought on the global society.

\section{Current State/Future}

A key distinction between the CSCW and GSS/CE research streams was that $\mathrm{CSCW}$ researchers held a normative view that processes should not be designed, but should emerge naturally, invented by participants for themselves on the fly. By contrast, GSS and CE research focused on designing processes with practitioners before work began to optimize the actions that groups wanted to take that would make them productive, and to minimize the actions groups did not want to take that would make them unproductive. That distinction may have arisen because early CSCW research focused on small groups of two to ten people, while early GSS research focused on groups of tens to hundreds of people. Research suggests that the utility of structure may increase with group size. Both approaches bore fruit.

Summarizing the short description of the history and the characteristics in the previous section, one sees the subfields in (research about) supporting collaboration as depicted in Table 1.

The defining element of CSCW and Social Computing is:

- Open processes - people will find new ways to use collaboration technology to achieve their goals.

Collaboration Engineering adds the issue of

- Designed processes - experts can help practitioners design better ways to use collaboration technology to achieve their goals.

There are, however also strong commonalities among CSCW, Social Computing, GSS, and Collaboration Engineering research: 
Table 1 Subfields in research about supporting collaboration

\begin{tabular}{|c|c|c|}
\hline $\mathrm{CSCW}$ & $\mathrm{CE}$ & Social Computing \\
\hline Small groups & Medium sized and large work groups & $\begin{array}{l}\text { (Very large) (non-work) groups and } \\
\text { communities }\end{array}$ \\
\hline $\begin{array}{l}\text { Collaborative work processes should } \\
\text { emerge on the fly }\end{array}$ & $\begin{array}{l}\text { Collaborative work processes can be designed to } \\
\text { optimize desired outcomes }\end{array}$ & $\begin{array}{l}\text { Work processes on this scale are not yet well } \\
\text { understood }\end{array}$ \\
\hline $\begin{array}{l}\text { Learn about how people use available } \\
\text { technology to support their collaborative } \\
\text { work processes }\end{array}$ & $\begin{array}{l}\text { Develop patterns, theories, and methodologies for } \\
\text { designing technology-supported collaborative } \\
\text { work practices }\end{array}$ & $\begin{array}{l}\text { Learn about social processes that emerge in } \\
\text { Social Computing, and how they are similar to } \\
\text { or different from processes in other media }\end{array}$ \\
\hline $\begin{array}{l}\text { Focus on openness of work process - } \\
\text { one must overcome structure by using/ } \\
\text { designing collaborative technologies }\end{array}$ & $\begin{array}{l}\text { Focus on structure of work process - one can work } \\
\text { with practitioners to design effective, efficient, } \\
\text { satisfying collaborative work processes and to } \\
\text { design technology to support them }\end{array}$ & $\begin{array}{l}\text { Focus on community - people find benefit in } \\
\text { associations with friends, family, and affinity } \\
\text { groups }\end{array}$ \\
\hline
\end{tabular}

- The value of collaboration - All branches of technology-supported collaboration research assume that people convene as groups to create value that they cannot create as individuals.

- Design solutions - All branches recognize that researchers must develop and test solutions. It is not sufficient to so study only the ways people can or do use existing technology.

- Mixed methods - Researchers in all these subfields have recognized that no single research approach can produce a full understanding of collaboration or collaboration technology. Three epistemologies prevail in academia. Each addresses different classes of research questions, and so has different disciplines, different research products, and different standards of rigor. Interpretivism addresses the meanings people ascribe to their experiences; criticalistist epistemology addresses questions of morals, ethics, and social justice; and causal epistemology questions causes and consequences. Within causal epistemology are the four modes of inquiry that comprise scientific method: exploratory research, theoretical research, experimental research, and applied science/ engineering research. None of these would be sufficient to answer the many complex questions that arise in the socio-technical milieu of collaboration. All must therefore be valued, nurtured, and practice rigorously by our field.

CSCW has traditionally studied interdependencies among collaborating human actors and computer systems. New CSCW systems like Shared Workspace Systems or (enterprise) Social Networks enable completely new divisions of labor between collaborating actors and computer systems in an organizational setting. Particular examples are crowdsourcing, open innovation or the inclusion of external experts in internal processes. This has important implications for organizational structures, management and motivation.
The distinction between CSCW and Social Computing is no longer strict - at CSCW conferences work on nonwork-group fields is presented and both fields focus on mixed method approaches to research. Due to this reason the terms are often used interchangeably - or as in our case and in the case of the annual ACM conference on CSCW in combination as "CSCW and Social Computing".

CSCW and CE, however, have not yet converged - the communities still develop their work in different conferences, and there is little exchange of knowledge between them. We, however, argue that this should change.

Some CSCW researchers believe that a priori structure of any kind will be harmful, although GSS/CE researchers have demonstrated that, under certain conditions, a welldesigned process can provide substantial improvements in efficiency and effectiveness. Likewise, researchers in Collaboration Engineering can benefit by learning from CSCW the subtle insights into the dynamics of emergent collaboration. People can be surprisingly creative and productive if they are provided with the appropriately designed processes - as current research on crowdsourcing shows. But people can also be surprisingly creative and productive when all engineered processes fail and they have to improvise based on unstructured social media platforms - as current research on disaster recovery after Hurricane Catherina or the flooding in Thailand shows. Finding the right mix of structure and leaving freedom for emergence remains a challenging task that both areas should join forces instead of ignoring one another.

There are early indicators that this is starting to happen: more recently, researchers in CSCW and Social Computing studies have discovered that structure can, indeed be helpful for people in open collaboration systems like Enterprise Social Networks or Wikis. In ESNs people report a longing for insights about how to overcome the malleability of the system. They ask for examples of successful ways to do useful work. In wikis it has been shown that data relevant to work is often more structured than that in 
consumer/social systems. So, when it comes to work, it can be seen as proven that structure is not anathema, and it is not panacea, it is just a tool. Wielded well, it can enhance outcomes for groups. Like any tool, it can also be wielded badly. It is past time for the CSCW and CE communities to join forces to sort out the conditions under varying degrees of structure or openness can enhance group outcomes. The re-integration of $\mathrm{CSCW}$ and $\mathrm{CE}$ into a bigger field will ignite a renaissance of research, as the research community synthesizes the insights from each branch into a grander understanding of collaboration and collaboration technology.

\section{Papers in this Special Issue}

We want this special issue on "CSCW and Social Computing" to give an overview of the current state of CSCW and Social Computing with a focus on research that studies new human-human work and networking patterns as well as new configurations of humans and computers.

The call resulted in sixteen paper submissions. Two of the submissions focused on looking at the consumer sector - and applying the findings to the work sector, the other submissions focused on the work sector only. The submissions both showed work on learning about how work is done or how existing tools influence work, and on designing new tools for supporting specific aspects of work.

From the 16 submissions to our call we have selected four papers spanning from classical CSCW issues to new Social Computing issues and application domains. The accepted papers also show different research paradigms.

The paper "Managed Wiki - A New Approach for Web 2.0" by Thomas Wöhner, Sebastian Köhler and Ralf Peters follows a Design Science approach to develop and evaluate a new solution to access rights for editing content in public and corporate information systems. On the example of wikis, an approach to automatically block or allow edits is presented, and evaluated on data from the German Wikipedia. There are surely differences between public and corporate systems, however such approaches might help greatly to keep the possibility to edit content in corporate systems up while maintaining a good feeling for quality as it is mentioned in different case studies on corporate wiki projects.

In "How (not) to Incent Crowd Workers - Payment Schemes and Feedback in Crowdsourcing" Tim Straub, Henner Gimpel, Florian Teschner and Christoph Weinhardt address the issue of crowdsourcing. They especially look at the challenge to properly incent worker effort to create value. Following an exploratory approach, the authors derive a model on worker performance in rank-order tournaments and present a series of real effort studies using experimental techniques on an online labor market to test the model and to compare dyadic tournaments to piece rate payments. Data suggests that on average dyadic tournaments do not improve performance compared to a simple piece rate for simple and short crowdsourcing tasks. Furthermore, giving feedback on the competitive position in such tournaments tends to be negatively related to workers' performance.

"Connect Me! Towards a Holistic Understanding of Social Connectedness in Enterprise Social Software" by Maurice Kügler, Sven Dittes, Stefan Smolnik and Alexander Richter is the first of two papers investigating Enterprise Social Networks. The authors performed a survey-based investigation among 174 employees of an international business software provider headquartered in Germany, and show that both reputation and a critical mass significantly influence employees' social connectedness. They further find that reputation's effect is significantly stronger than critical mass's effect and that social connectedness influences employees' individual performances positively.

In "From Top to Bottom: Investigating the Changing Role of Hierarchy in Enterprise Social Networks" Stefan Stieglitz, Christian Meske and Kai Riemer present an explorative theory developing case study that addresses the question of how the user's position in an organizations hierarchy and the user's contributions to a network are connected, and how these parameters influence the ability to elicit responses from other users of an Enterprise Social Network. The authors draw on a unique data set of more than 110,000 messages collected from an ESN platform at Deloitte Australia.

To complement the presentation of the current state and future directions of the field we conducted interviews with two senior researchers that have worked several years on understanding and designing support for collaboration and communication - getting real voices on what the most interesting achievements and future goals of the field are from two different perspectives. The first interview is with Jonathan Grudin. He was one of the first activists in the field of CSCW, authored or co-authored some of the first and most influential papers and still has a clear vision of where the field should go to. He points out that in recent years, the CSCW community turned its attention to the consumer sector, from which it derived many new insights. Without leaving that sector behind, CSCW should nonetheless turn again to its roots, bringing the insights it derived from the consumer sector to see how those insights could benefit the organizational setting.

The second interview is with Jay Nunamaker, one of the core figures from the field of Management Information Systems, who did a lot of work on collaboration. He explicitly calls for an end of the schism between CSCW 
community and the GSS/collaboration engineering community. We editors wholeheartedly support this call and see the German-rooted BISE community as very well positioned to help overcome this schism.

\section{References}

Bowers J, Benford S (1991) Studies in computer-supported cooperative work: theory, practice, and design. Elsevier, Amsterdam

Brenner W, Karagiannis D, Kolbe L, Krüger J, Lamberti H-J, Leifer L, Leimeister JM, Österle H, Petrie C, Plattner H, Schwabe G, Uebernickel F, Winter R, Zarnekow R (2014) User, use \& utility research - the digital user as new design perspective in business and information systems engineering. Bus Inf Syst Eng 6(1):55-61

Briggs RO, de Vreede GJ, Nunamaker J Jr (2003) Collaboration engineering with ThinkLets to pursue sustained success with group support systems. J Manag Inf Syst 19(4):31-64

Briggs RO, Kolfschoten GL, de Vreede GJ, Lukosch SG, Albrecht CC (2013) Facilitator-in-a-box: process support applications to help practitioners realize the potential of collaboration technology. J Manag Inf Syst 29(4):159-194

Briggs RO, Kolfschoten GL, de Vreede GJ, Albrecht C, Lukosch SG, Dean DL (2014) A six layer model of collaboration. In: Nunamaker JF Jr, Romano NC Jr, Briggs RO (eds) Collaboration systems: concept, value, and use. Sharp, Armonk
Coates T (2005) An addendum to a definition of social software. http://www.plasticbag.org/archives/2005/01/an_addendum_to_ a_definition_of_social_software/. Accessed 1 Oct 2010

de Vreede GJ, Briggs R (2009) Collaboration engineering: foundations and opportunities. J Assoc Inf Syst 10(special issue):121-137. http://aisel.aisnet.org/cgi/viewcontent. cgi? article=1499\&amp; context=jais. Accessed 4 Feb 2015

Dix AJ, Finley J, Abowd GD, Beale R (1993) Human-computer interaction. Prentice Hall, New York

Dourish P, Belotti V (1992) Awareness and coordination in shared workspaces. In: Proc conf computer-supported coop work. ACM, New York, pp 107-114

Koch M, Gross T (2006) Computer-supported cooperative work concepts and trends. In: Proc conf assoc inf manag. lecture notes in informatics (LNI) P-92. Koellen, Bonn

Kolfschoten GL, de Vreede GJ (2009) A design approach for collaboration processes: a multimethod design science study in collaboration engineering. J Manag Inf Syst 26(1):225-256

Malone TW, Crowston K (1992) Towards an interdisciplinary theory of coordination. Technical Report CSS TR\#120. Center for Coordination Science, Sloan School of Management, MIT, Cambridge

Misch A (2001) Context-oriented communication support in a collaborative learning environment - Kolumbus is born. In: Proc 24th inf syst res semin Scand, vol 2, pp 48-58

Nunamaker JF Jr, Konsynski BR Jr, Ho T, Singer CA (1976) Computer-aided analysis and design of information systems. Commun ACM 19(12):674-687 